\title{
Inducible Nitric Oxide Synthase (iNOS) Is a Novel Negative Regulator of Hematopoietic Stem/Progenitor Cell Trafficking
}

\author{
Mateusz Adamiak $^{1,4}$ • Ahmed Abdelbaset-Ismail ${ }^{1}$. Joseph B. Moore $\mathrm{IV}^{2} \cdot \mathrm{J} \mathrm{Zhao}^{2}$ • \\ Ahmed Abdel-Latif $^{3} \cdot$ Marcin Wysoczynski $^{2} \cdot$ Mariusz Z. Ratajczak ${ }^{1,4}$
}

Published online: 17 October 2016

(C) The Author(s) 2016. This article is published with open access at Springerlink.com

\begin{abstract}
Nitric oxide (NO) is a gaseous free radical molecule involved in several biological processes related to inflammation, tissue damage, and infections. Based on reports that NO inhibits migration of granulocytes and monocytes, we became interested in the role of inducible NO synthetase (iNOS) in pharmacological mobilization of hematopoietic stem/ progenitor cells (HSPCs) from bone marrow (BM) into peripheral blood (PB). To address the role of NO in HSPC trafficking, we upregulated or downregulated iNOS expression in hematopoietic cell lines. Next, we performed mobilization studies in $\mathrm{iNOS}^{-/-}$mice and evaluated engraftment of $\mathrm{iNOS}^{-/-}$HSPCs in wild type (control) animals. Our results indicate that iNOS is a novel negative regulator of hematopoietic cell migration and prevents egress of HSPCs into PB during mobilization. At the molecular level, downregulation of iNOS resulted in downregulation of heme oxygenase 1 (HO-1), and, conversely, upregulation of iNOS enhanced HO-1 activity. Since HO-1 is a negative regulator of cell migration, the inhibitory effects of iNOS identified by us can be
\end{abstract}

Electronic supplementary material The online version of this article (doi:10.1007/s12015-016-9693-1) contains supplementary material, which is available to authorized users.

Mariusz Z. Ratajczak

mzrata01@louisville.edu

1 Stem Cell Institute at James Graham Brown Cancer Center, University of Louisville, 500 S. Floyd Street Rm. 107, Louisville, KY 40202, USA

2 Institute of Molecular Cardiology, University of Louisville, Louisville, KY, USA

3 Division of Cardiovascular Medicine, Gill Heart Institute, University of Kentucky, Lexington, KY, USA

4 Department of Regenerative Medicine, Warsaw Medical University, Warsaw, Poland at least partially explained by its enhancing the HO-1 level in BM cells.

Keywords iNOS $\cdot \mathrm{NO} \cdot$ Stem cell mobilization $\cdot$ Stem cell homing $\cdot$ Complement cascade $\cdot \mathrm{HO}-1$

\section{Introduction}

Evidence has accumulated that mobilization of hematopoietic stem/progenitor cells (HSPCs) from bone marrow (BM) into peripheral blood (PB) is triggered by activation of the complement cascade (ComC) [1-4]. In our previous work we demonstrated that this process, which occurs in response to certain pharmacological drugs, such as granulocyte colony stimulating factor (G-CSF) or the CXCR4 antagonist (AMD3100), is inhibited by heme oxygenase 1 (HO-1) activity $[5,6]$. HO-1 metabolizes heme into biliverdin, $\mathrm{CO}$, and iron, and the first two metabolites have anti-inflammatory properties, including inhibition of the ComC [7-9]. Consistent with an inhibitory effect of HO-1 on mobilization of HSPCs, HO- $1^{-/}$mice are easy mobilizers [6], and downregulation of HO-1 activity in HSPCs enhances their homing after transplantation [5].

Inducible nitric oxide synthase (iNOS, also known as NOS2), like HO-1, is upregulated in response to inflammation, tissue injury, and infections and generates nitric oxide (NO), which is a gaseous free radical molecule $[10,11]$. Overall, NO is also synthesized by two other nitric oxide synthase isoforms, neuronal NOS (nNOS, also known as NOS1) and endothelial NOS (eNOS, also known as NOS3), which are constitutively expressed and calcium dependent [11-14]. In contrast to nNOS and eNOS, iNOS is calcium independent and produces more NO than the other isoforms $[11,14]$. Interestingly, the ComC upregulates iNOS, while NO 
regulates blood flow by stimulating vascular relaxation. It is also involved in neurotransmission and immune-response facilitation and exerts anti-thrombotic and anti-inflammatory effects [10, 15-18].

Interestingly, iNOS activity is enhanced during ComC activation [16], which is a crucial element of innate immunity, and its cleavage fragments, $\mathrm{C} 3$ and $\mathrm{C} 5$ (giving rise to $\mathrm{C} 3 \mathrm{a}$ and C5a, respectively), orchestrate the egress of HSPCs from BM into peripheral blood (PB) and their homing after transplantation $[1-4,19]$. However, these pro-mobilization and prohoming effects of $\mathrm{C} 3 \mathrm{a}$ and $\mathrm{C} 5 \mathrm{a}$ are not related directly to the chemoattraction of HSPCs but rather indirectly to i) the induction of a proteolytic and lipolytic microenvironment in BM, ii) the chemoattraction of granulocytes and monocytes that pave the way for HSPCs to cross the BM-sinusoid endothelium barrier, and iii) increasing the level of chemotactic factors in blood plasma, including sphigosine-1-phosphate (S1P) and ceramide-1-phosphate (C1P) [2, 20-28]. In addition to the ComC, iNOS is also induced in response to several inflammatory cytokines (TNF- $\alpha$, IL-1 $\beta$, IFN- $\gamma$ ), lipopolysaccharide (LPS) endotoxin, hypoxia, and oxidative stress [10, 29].

Mobilization studies in $\mathrm{eNOS}^{-/-}$mice revealed that eNOS constitutively expressed in endothelium is required for optimal vascular endothelial growth factor (VEGF)-induced mobilization of endothelial progenitor cells (EPCs) and protection from mortality after myelosuppression [30]. However, no mobilization studies have been performed so far to assess the role of inducible hematopoietic cell-expressed iNOS in the mobilization of HSPCs.

Based on the foregoing, we became interested in the potential role of iNOS in the mobilization of HSPCs. This interest was further motivated by two considerations. First, it has been reported that NO inhibits migration of granulocytes and monocytes, which, as mentioned above, are crucial in facilitating egress of HSPCs across the BM-PB barrier [11, 15, 31 , 32]. Second, NO, which promotes inflammation, has also some anti-inflammatory activity limiting immune response $[11,15]$, and inflammation is one of the driving forces of HSPC mobilization.

To fill in this knowledge gap, we upregulated or downregulated iNOS expression in hematopoietic cells. Next, we performed mobilization studies in $\mathrm{iNOS}^{-/}$mice and, in parallel, evaluated the engraftment of iNOS $^{-/-}$HSPCs in wild type control animals. Since activation of the ComC is negatively regulated by heme oxygenase 1 (HO-1) $[6,33]$, and the ComC downregulates HO-1 [33], we tested the involvement of HO-1 in iNOS-mediated cell trafficking.

We report here for a first time that activation of iNOS negatively regulates hematopoietic cell migration and prevents egress of HSPCs into PB during mobilization. Moreover, our studies in employing hematopoietic chimeras revealed that this iNOS effect depends on its expression in hematopoietic cells.

\section{Materials and Methods}

Animals In our experiments we employed female C57BL/6 J wild-type (WT) and B6.129P2-Nos2tm1 Lau/J (iNOS ${ }^{-/}$) 6-8week-old mice purchased from The Jackson Laboratory (Bar Harbor, ME, USA). Animal studies were approved by the Animal Care and Use Committee of the University of Louisville (Louisville, KY, USA).

Murine Bone Marrow-Derived Mononuclear Cells BMMNCs were obtained by flushing femurs and tibias of pathogen-free WT or iNOS ${ }^{-1-}$ female mice. Cells were lysed with BD Pharm Lyse buffer (BD Biosciences, San Jose, CA, USA) to remove red blood cells (RBCs), washed, and resuspended in appropriate media for further experiments. When necessary, murine Sca- $1^{+}$cells were isolated as described [21].

Cell Lines HEL and K562 cell lines were propagated in RPMI 1640 medium (Life Technologies), supplemented with $10 \%$ FBS (Seradigm), $1 \times$ GlutaMAX ${ }^{\mathrm{TM}}$ (Life Technologies), and $1 \times$ penicillin-streptomycin (Life Technologies). All cell lines were passaged every 2-3 days to maintain concentrations in the approximate range of $200,000-800,000$ cells per $\mathrm{ml}$.

\section{Human NOS2 Overexpression and shRNA-Mediated}

Knockdown Lentiviral particles utilized in the establishment of NOS2-overexpressing or NOS2-knockdown cell lines were derived using the ViraPower ${ }^{\mathrm{TM}}$ Lentiviral Expression System (Life Technologies) according to the manufacturer's protocol. Subsequently, HEL or K562 suspension cells were transduced via spinoculation. Briefly, cells $\left(2 \times 10^{5}\right.$ in $2 \mathrm{ml}$ of complete medium) were mixed with $2 \mathrm{ml}$ of viral supernatant and polybrene $(8 \mu \mathrm{g} / \mathrm{ml}$ final concentration). The cell-virus suspension was then centrifuged at $800 \mathrm{xg}$ for $2 \mathrm{~h}$ at $37^{\circ} \mathrm{C}$. At the conclusion of spinoculation, the viral medium was aspirated, and the cells were resuspended in complete medium and then incubated in a $37^{\circ} \mathrm{C}$ incubator $\left(5 \% \mathrm{CO}_{2}\right)$. Seventy-two hours post viral transduction, the cells underwent antibioticmediated selection using puromycin $(1 \mu \mathrm{g} / \mathrm{ml})$. All cell lines were maintained under antibiotic selection pressure throughout the duration of their expansion prior to experimentation. A detailed list of the lentiviral vectors employed is found in Table 1.

Mobilization Studies WT and iNOS ${ }^{-/}$mice were injected subcutaneously (s.c.) with $100 \mu \mathrm{g} / \mathrm{kg}$ G-CSF (Amgen, Thousand Oaks, CA, USA) daily for 3 (short mobilization) or 6 (long mobilization) days or one dose of AMD3100 (Sigma-Aldrich, $5 \mathrm{mg} / \mathrm{kg}$, intraperitoneally). At $6 \mathrm{~h}$ after the last G-CSF administration or at $1 \mathrm{~h}$ after AMD3100 injection, the mice were bled from the retro-orbital plexus for hematology analysis, and peripheral blood (PB) was obtained from the vena cava with a 25 -gauge needle and 1 -ml syringe containing 
Table 1 NOS2 overexpression and shRNA-knockdown viral vectors

\begin{tabular}{lll}
\hline Human NOS2 overexpression & Vector construct & Company \\
\hline Control vector (empty vector) & pLenti6-MCS-GFP-2 A-Puro & N/A \\
Human NOS2 vector (Accession BC130283) & pLenti-GIII-CMV-Human NOS2-GFP-2 A-Puro & abm® inc. \\
Human NOS2 shRNA knockdown & Vector construct & Company \\
Control shRNA (non-target control shRNA) & pLenti6-U6-NT shRNA-GFP-2 A-Puro2 & N/A \\
NOS2 Mission® TRC shRNA (shRNA 1) & Mission shNOS2 (TRCN0000231570) & Sigma-Aldrich® \\
NOS2 Mission® TRC shRNA (shRNA 2) & Mission shNOS2 (TRCN0000231573) & Sigma-Aldrich® \\
\hline
\end{tabular}

$50 \mu \mathrm{l}$ of $100 \mathrm{mM}$ EDTA. Mononuclear cells (MNCs) were obtained by hypotonic lysis of RBCs in BD Pharm Lyse buffer (BD Biosciences).

Fluorescence-Activated Cell Sorting (FACS) Analysis The following monoclonal antibodies were used to perform staining of $\mathrm{Lin}^{-} / \mathrm{Sca} 1^{+} / \mathrm{c}-\mathrm{Kit}^{+}(\mathrm{SKL})$ cells and $\mathrm{Lin}^{-} / \mathrm{Sca}-1^{+} / \mathrm{CD} 45^{+}$ (hematopoietic stem cells [HSCs]): FITC-anti-CD117 (also known as c-Kit, clone 2B8; BioLegend, San Diego, CA, USA) and PE-Cy5-anti-mouse Ly-6 A/E (also known as Sca-1, clone D7; eBioscience, San Diego, CA, USA). All anti-mouse lineage markers, (Lin) anti-CD45R/B220 (clone RA3-6B2), anti-Ter-119 (clone TER-119), anti-CD11b (clone M1/70), anti-T cell receptor $\beta$ (clone H57-597), anti-Gr-1 (clone RB6-8C5), anti-TCR $\gamma \delta$ (clone GL3), and anti-CD45 (clone 30-F11), were purchased from BD Biosciences and conjugated with $\mathrm{PE}$ as described. Staining was performed in RPMI 1640 medium containing $2 \%$ FBS. All monoclonal antibodies (mAbs) were added at saturating concentrations, and the cells were incubated for $30 \mathrm{~min}$ on ice, washed twice, and analyzed with an LSR II flow cytometer (BD Biosciences).

Evaluation of HSPC Mobilization For evaluation of circulating colony-forming unit-granulocyte/macrophage (CFUGM) and SKL cells the following formula was used: (number of white blood cells [WBCs]) x number of CFU-GM colonies)/number of WBCs plated $=$ number of CFU-GM per $\mu$ l of $\mathrm{PB}$; and (number of WBCs $\mathrm{x}$ number of SKL cells)/number of gated $\mathrm{WBCs}=$ number of SKL cells per $\mu \mathrm{l}$ of PB.

Short-Term Homing Experiments Lethally irradiated WT mice ( $\gamma$-irradiation at $1000 \mathrm{cGy}) 24 \mathrm{~h}$ after irradiation were transplanted (by tail vein injection) with $3 \times 10^{6} \mathrm{BM}$ cells from WT or iNOS ${ }^{-/-}$mice labeled with the PKH67 green fluorescent cell linker according to the manufacturer's protocol (Sigma-Aldrich, St Louis, MO, USA). At $24 \mathrm{~h}$ after transplant, BM cells from the femurs were isolated via FicollPaque and divided, and $30 \%$ of the cells were analyzed by FACS. The rest of the cells were plated in serum-free methylcellulose cultures and stimulated to grow CFU-GM colonies with $\mathrm{mGM}-\mathrm{CSF}(25 \mathrm{ng} / \mathrm{ml})$ and $\mathrm{mIL}-3(10 \mathrm{ng} / \mathrm{ml})$. After
7 days of incubation $\left(37{ }^{\circ} \mathrm{C}, 95 \%\right.$ humidity, and $\left.5 \% \mathrm{CO}_{2}\right)$, the number of colonies was scored under an inverted microscope.

Evaluation of Engraftment For short-term engraftment experiments, WT mice were irradiated with a $1000 \mathrm{cGy}$ of $\gamma$ irradiation. After $24 \mathrm{~h}$, mice were transplanted by tail vein injection with $1.5 \times 10^{5} \mathrm{BM}$ cells from $\mathrm{WT}$ or $\mathrm{iNOS}^{-/}$mice. Femora of transplanted mice were flushed with PBS on day 12 post-transplant. Purified via Ficoll-Paque, BM cells were plated in serum-free methylcellulose cultures and stimulated to grow CFU-GM colonies with mGM-CSF $(25 \mathrm{ng} / \mathrm{ml})$ and IL$3(10 \mathrm{ng} / \mathrm{ml})$. After 7 days of incubation $\left(37^{\circ} \mathrm{C}, 95 \%\right.$ humidity, and $5 \% \mathrm{CO}_{2}$ ) the number of colonies was scored under an inverted microscope. Spleens were also removed, fixed in Telesyniczky's solution for CFU-S assays, and the colonies on the surface of the spleen counted.

Recovery of Leukocytes and Platelets WT mice were lethally irradiated, and after $24 \mathrm{~h}$, the animals were transplanted by tail vein injection with $2.5 \times 10^{5} \mathrm{BM}$ cells from WT or iNOS ${ }^{-}$ - mice. Transplanted mice were bled at various intervals from the retro-orbital plexus to obtain samples for white blood cell and platelet counts. Fifty microliters of PB was taken from the retro-orbital plexus of the mice into EDTA-coated Microvette tubes (Sarstedt Inc., Newton, NC, USA) and run within $2 \mathrm{~h}$ of collection on a HemaVet 950FS hematology analyzer (Drew Scientific Inc., Oxford, CT, USA).

Western Blotting K562-pCMV6-hiNOS, HEL-pCMV6hiNOS, K562-shiNOS, HEL-shiNOS and their respective control cells were harvested, centrifuged, and washed with cold PBS. For protein extraction, the cells were treated with cold RIPA lysis buffer, supplemented with protease and phosphatase inhibitors (Santa Cruz Biotech), for $30 \mathrm{~min}$ on ice and centrifuged at $15,000 \mathrm{rpm}$ at $-4{ }^{\circ} \mathrm{C}$ for $15 \mathrm{~min}$. The total protein concentration per sample was measured using the Pierce BCA Protein Assay Kit (Pierce, Rockford, IL) and Multimode Analysis Software (Beckman Coulter). The concentration-adjusted extracted proteins $(50 \mu \mathrm{g} / \mathrm{each}$ sample $)$ were then separated on a 4-12\% SDS-PAGE gel and transferred to a PVDF membrane (Bio-Rad). All membranes were 
blocked with $2.5 \%$ nonfat dry milk in Tris-buffered saline containing $0.1 \%$ Tween (TBST) for $1 \mathrm{~h}$ at room temperature. After washing with TBST, the membranes were incubated with rabbit anti-HO-1 polyclonal antibody (Enzo Life Sciences, NY, USA; diluted 1:1000) overnight at $4{ }^{\circ} \mathrm{C}$. To assure equal protein loading in each lane, the blots were then reprobed with a rabbit anti- $\beta$-actin monoclonal antibody (Novus Biologicals, USA; diluted 1:1000). All membranes were then treated with enhanced chemiluminescence (ECL) reagent (Amersham Life Sciences) and subsequently exposed to film (Hyperfilm, Amersham Life Sciences). For protein band visualization, an automatic film developer supplied with fresh warm developer and fixer solutions was used. The intensities of the blots obtained were quantified using ImageJ software (National Institutes of Health, Bethesda, MD, USA).

\section{Real-Time Quantitative Reverse-Transcription PCR of} Cell Lines Total RNA was isolated with the RNeasy Kit (Qiagen, Valencia, CA, USA) from hematopoietic cells in which iNOS was up- and downregulated and their respective control cells. Expression of iNOS at the mRNA level was also evaluated in hematopoietic cell lines in which HO-1 was upand downregulated in comparison with control cell lines. The RNA was reverse-transcribed with MultiScribe reverse transcriptase and oligo-dT primers (Applied Biosystems, Foster City, CA, USA). Quantitative assessment of mRNA levels was done by real-time RT-PCR using an ABI 7500 instrument with Power SYBR Green PCR Master Mix reagent. PCR conditions were as follows: $95^{\circ} \mathrm{C}(15 \mathrm{~s}), 40$ cycles at $95^{\circ} \mathrm{C}(15 \mathrm{~s})$, and $60^{\circ} \mathrm{C}(1 \mathrm{~min})$. According to melting point analysis, only one PCR product was amplified under these conditions. The relative quantity of a target, normalized to the endogenous $\beta 2$ microglobulin gene as control and relative to a calibrator, is expressed as $2^{-\mathrm{DDCt}}$ (fold difference), where $\mathrm{Ct}$ is the threshold cycle, $\mathrm{DCt}=(\mathrm{Ct}$ of target genes $)-(\mathrm{Ct}$ of the endogenous control gene, $\beta 2$-microglobulin $)$, and DDCt $=(\mathrm{DCt}$ of samples for the target gene) - (DCt of the calibrator for the target gene). The following primer pairs were used for analysis of iNOS expression: 5-CAG CGG GAT GAC TTT CCA A-3 (forward) and 5- AGG CAA GAT TTG GAC CTG CA-3 (reverse). For HO-1 expression: 5-GGG TGA TAG AAG AGG CCA AGA CT-3 (forward) and 5-AGC TCC TGC AAC TCC TCA AGA-3 (reverse).

Transwell Chemotaxis Assay To render the cells quiescent, K562 and HEL cell lines were incubated overnight in RPMI 1640 medium containing $0.5 \%$ bovine serum albumin (BSA). BMMNCs from WT and iNOS ${ }^{-/-}$mice were made quiescent for $3 \mathrm{~h}$ in the same medium, and some were incubated for $1 \mathrm{~h}$ with different doses of the iNOS inhibitor, $\mathrm{N}^{6}$-(1-Iminoethyl)L-lysine hydrochloride (L-NIL; Tocris Bioscience, Bristol, UK). Subsequently, cells were washed and resuspended in assay medium (RPMI 1640 with $0.5 \%$ BSA). Cells were aliquoted at a density of $1 \times 10^{5}$ cells in $100 \mu \mathrm{l}$ with an 8 - $\mu \mathrm{m}$ syringe (for human cell lines) and $1 \times 10^{6}$ cells in $100 \mu \mathrm{l}$ with a 5 - $\mu \mathrm{m}$ syringe (for murine BMMNCs) into polycarbonate membrane inserts in a Costar Transwell 24-well plate (Costar Corning, Cambridge, MA, USA) and incubated for $3 \mathrm{~h}$ of chemotaxis at $37^{\circ} \mathrm{C}$. medium with $0.5 \% \mathrm{BSA}$ $(650 \mu \mathrm{l} /$ well) containing no chemoattractant (negative control), stromal-derived factor 1 (SDF-1, $50 \mathrm{ng} / \mathrm{ml}$ ), sphingosine-1-phosphate (S1P, $0.1 \mu \mathrm{M})$, ceramide-1phosphate $(\mathrm{C} 1 \mathrm{P}, 100 \mu \mathrm{M})$, or adenosine triphosphate (ATP, $0.5 \mu \mathrm{g} / \mathrm{ml}$ ) was added to the lower chambers of the plate. After $3 \mathrm{~h}$ of incubation, the cells from the lower chambers were collected. The number of human cell lines and murine BM-derived cells were scored by FACS (Becton Dickinson, Franklin Lakes, NJ, USA). Briefly, the cells were gated according to their forward scatter (FSC) and side scatter (SSC) parameters and counted during a 30-s acquisition at a high flow rate. After chemotaxis from the lower chamber, the murine cells were resuspended in human methylcellulose base medium provided by the manufacturer (R\&D Systems, Minneapolis, MN, USA), supplemented with murine and human granulocyte/macrophage colony stimulating factor (GMCSF, $25 \mathrm{ng} / \mathrm{ml}$ ) and interleukin-3 (IL-3, $10 \mathrm{ng} / \mathrm{ml}$ ) for determining the number of CFU-GM colonies. Cultures were incubated for 7 days $\left(37^{\circ} \mathrm{C}, 95 \%\right.$ humidity, and $\left.5 \% \mathrm{CO}_{2}\right)$, at which time they were scored under an inverted microscope for the number of colonies.

Fibronectin Adhesion Assay Human cell lines and murine BMMNCs at a density of $5 \times 10^{4} / 100 \mu 1$ were made quiescent overnight or for $3 \mathrm{~h}$, respectively, and some were next incubated with different doses of L-NIL for $1 \mathrm{~h}$. Subsequently cells were washed by centrifugation and resuspended in RPMI1640 medium. Cell suspensions were added directly to 96well plates that had been coated before the experiment with fibronectin $(10 \mu \mathrm{g} / \mathrm{ml})$, incubated overnight at $4{ }^{\circ} \mathrm{C}$, and then blocked with medium containing $0.5 \%$ BSA for $2 \mathrm{~h}$. After $15 \mathrm{~min}$ at $37^{\circ} \mathrm{C}$, the non-adherent cells were then washed from the wells, and all adherent cells were counted using an inverted microscope.

Measurement of Intracellular Nitric Oxide (NO) K562pCMV6-hiNOS, HEL-pCMV6-hiNOS, K562-shiNOS, HEL-shiNOS, RAJI-pCMV6-hHO-1, RAJI-shHO-1, and their respective control cell lines were centrifuged and suspended in their culture medium in poly-D-lysine-coated wells $\left(15 \times 10^{4}\right.$ cells/well $)$ of 96-well plates. Each cell line was individually evaluated for NO levels using the Cell Meter ${ }^{\mathrm{TM}}$ Orange Fluorimetric Intracellular Nitric Oxide Assay Kit (AAT Bioquest, \#16,350). The loaded plates were centrifuged at $800 \mathrm{rpm}$ for $2 \mathrm{~min}$. Next, cells were incubated with Nitrixyte ${ }^{\mathrm{TM}}$ Orange probe working solution for $30 \mathrm{~min}$ at $37^{\circ} \mathrm{C}$ to detect free $\mathrm{NO}$ in the cells. After assay buffer II was 
added, the orange fluorescence signals were then measured using a microplate reader at an excitation wavelength of $540 \mathrm{~nm}$ and an emission wavelength of $590 \mathrm{~nm}$ (cut off at $570 \mathrm{~nm}$ ) in bottom-read mode.

Statistical Analysis All results are presented as mean \pm SD. Statistical analysis of the data was done using Student's $t$-test for unpaired samples (Excel, Microsoft Corp., Redmond, WA, USA) with a value of $p \leq 0.05$ considered significant.

\section{Results}

\section{Upregulation of iNOS in Established Hematopoietic Cell Lines Impairs their Chemotactic Response to SDF-1 and S1P Gradients and Enhances Cell Adhesion}

To address the effect of iNOS on migration and adhesion of hematopoietic cells, we established two human hematopoietic cell lines in which iNOS had been overexpressed after transducing cells with an iNOS-encoding vector. Figure 1A shows real time RT-PCR results in which iNOS was upregulated in HEL and K562 cell lines, and these cells expressed free NO at higher levels (Fig. 1B). Moreover, in functional assays iNOS overexpression was correlated with enhanced adhesion of cells to fibronectin-coated plates (Fig. 1C) and, more importantly, had reduced migration in response to SDF-1 and S1P gradients (Fig. 1D).

\section{Downregulation of iNOS in Established Hematopoietic Cell Lines Increases their Chemotactic Response to SDF-1 and S1P Gradients and Impairs Cell Adhesion}

Next, we successfully downregulated iNOS expression in the same HEL and K562 cells by employing a shRNA strategy. Figure 2A shows real-time RT-PCR results for iNOS mRNA expression, and Fig. 2B shows the level of free NO in these cells. We found that downregulation of iNOS correlated with decreased adhesion to fibronectin-coated plates (Fig. 2C) and enhanced migration in response to SDF-1 and S1P gradients (Fig. 2D).

\section{iNOS-Deficient Mice Are easily Mobilized by G-CSF and AMD3100}

Based on the above observations that iNOS modulates cell migration, we moved to a murine model of iNOS deficiency and employed $\mathrm{iNOS}^{-/-}$animals for in vivo studies. Supplementary Fig. 1 shows that the iNOS-deficient mice employed in our studies have normal PB cell counts (Supplementary Fig. 1A), red blood cell parameters (Supplementary Fig. 1B), and numbers of bone marrowresiding HSPCs (Supplementary Fig. 1C) and clonogenic progenitors (Supplementary Fig. 1D) compared with WT animals under steady-state conditions.

Next, we performed in vivo mobilization experiments. Figure 3 shows that $\mathrm{iNOS}^{-/-}$mice display enhanced 3-day (short) G-CSF-induced (Fig. 3A), 6-day (long) G-CSFinduced (Fig. 3B), and AMD3100-induced mobilization (Fig. 3C). This result indicates that these mice are easily mobilized and that iNOS may exert negative effects on the egress of HSPCs from BM into PB. These results correspond with an enhanced responsiveness of BMMNCs (Fig. 4A) and clonogeneic CFU-GMs (Fig. 4B) to HSPC chemoattractants, including SDF-1, S1P, C1P, and ATP.

\section{iNOS $^{-/}$BMMNCs Show Enhanced Homing and Engraftment in WT Animals}

Next, we performed homing studies employing PKH67labeled $\mathrm{iNOS}^{-/-}$and WT control mouse-derived BMMNCs transplanted into lethally irradiated WT animals. Twentyfour hours after transplantation, we observed an increased number of transplanted $\mathrm{PKH}_{6} 7^{+}$cells from iNOS-deficient mice as well as an increased number of clonogenic progenitors that were able to grow CFU-GM colonies after isolation from $\mathrm{BM}$ and plating in methylcellulose cultures (Fig. 5A).

In parallel, we sacrificed some of the animals on day 12 after transplantation and evaluated the number of colonyforming units in spleen (CFU-S) and the content of clonogenic CFU-GM progenitors in BM (Fig. 5B). Again, we observed a statistically significant beneficial effect of iNOS deficiency on short-term engraftment. Thus, both statistically significant enhanced homing and short-term engraftment of iNOS-deficient $\mathrm{BM}$ cells are correlated with enhanced migration of these cells in response to hematopoietic chemoattractant gradients, as shown in Fig. 4.

Finally, we evaluated the short term engraftment of BMMNCs from iNOS ${ }^{-/-}$mice by measuring the kinetics of leukocyte (Fig. 6A) and platelet (Fig. 6B) recovery in these animals. We found that mice transplanted with $\mathrm{iNOS}^{-/}$BMMNCs had a significantly accelerated recovery of leukocyte and platelet counts in peripheral blood.

Downregulation of iNOS in Murine BMMNCs by L-NIL, a Small-Molecule Inhibitor that Increases their Migration in Response to SDF-1 and S1P Gradients

Based on encouraging results with iNOS-downregulated cell lines and homing/engraftment studies with iNOS ${ }^{-/}$ BMMNCs, we exposed murine BMMNCs to nontoxic doses of the small-molecule iNOS inhibitor L-NIL (Supplementary Fig. 2) and evaluated the responsiveness of these cells to SDF1 and S1P homing gradients. Again, inhibition of iNOS in murine BMMNCs resulted in enhanced migration (Fig. 7A, B) and decreased adhesion to fibronectin-coated plates 


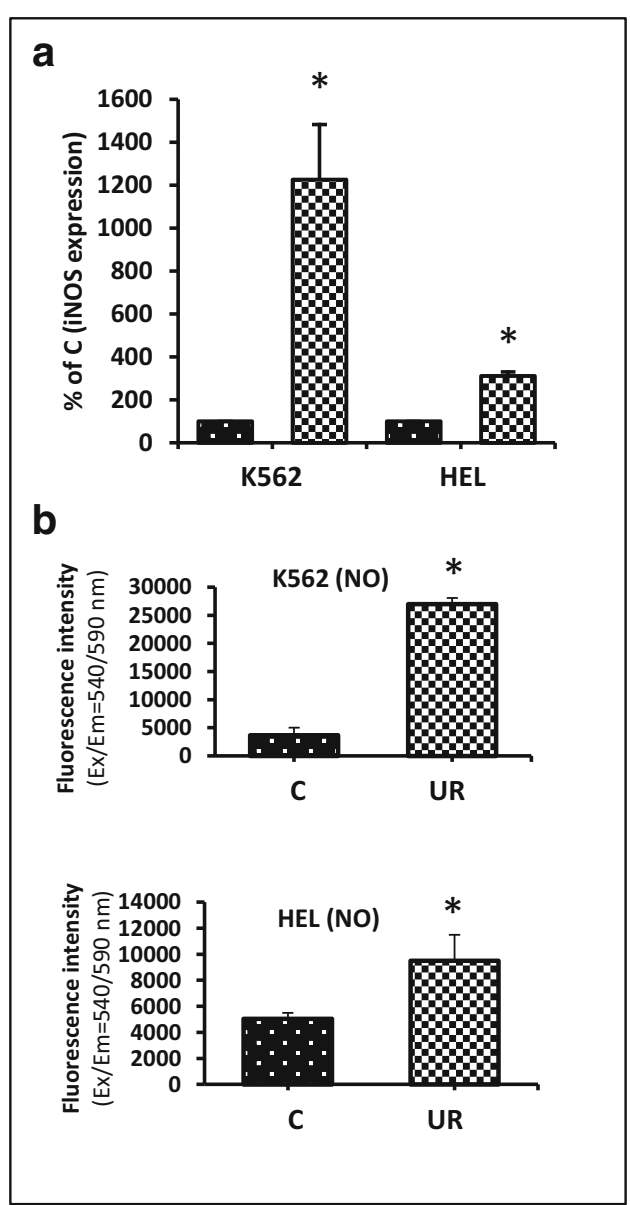

Fig. 1 Influence of iNOS upregulation on chemotaxis and adhesion of human hematopoietic cell lines (K562 and HEL). Panel A. iNOS expression was evaluated at the mRNA level by real-time PCR. Results from three independent experiments are pooled together. Panel B. Measurement of NO levels in the tested cells lines. $* p \leq 0.005$. Panel C. Fibronectin adhesion assay. The number of adherent cells is indicated,

(Fig. 7C). These results indicate that iNOS expression can be successfully modulated by small-molecule inhibitors and potentially employed to accelerate the homing of HSPCs. More importantly, we found that exposure of murine Sca- $1^{+}$cells and BMMNCs to L-NIL resulted in downregulation of $\mathrm{HO}-1$ (Fig. 7D).

\section{HO-1 Is Upregulated in Hematopoietic Cells with iNOS Overexpression and Expressed at Lower Levels in Cell Lines with iNOS Downregulation}

We have previously reported that $\mathrm{HO}-1$ is a negative regulator of cell trafficking and an inhibitor of ComC activation [6,33]. Therefore, we became interested in the potential relationship between expression of iNOS and HO-1 activity. As shown in Fig. 8, upregulation of iNOS in HEL and K-562 cells leads to an increase in HO-1 expression at the protein (Fig. 8A) and mRNA levels (Fig. 8B). By contrast, downregulation of iNOS
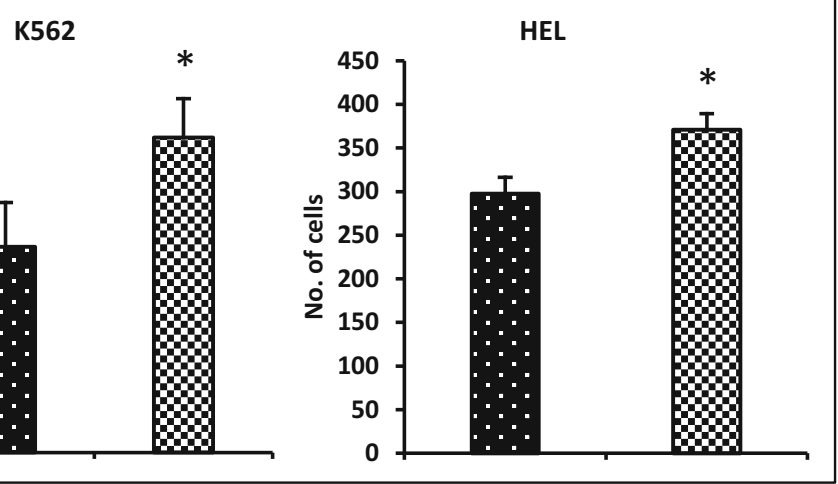

cell line (C) GiNOS upregulated cell line (UR)

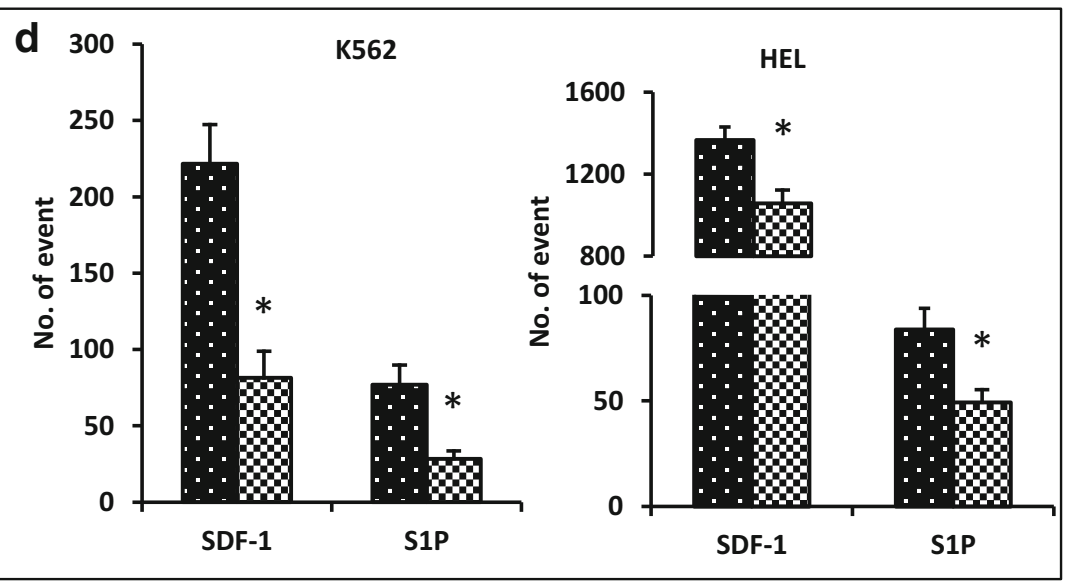

and results from three separate experiments are pooled together. $* p \leq 0.01$. Panel D. The chemotactic responsiveness of iNOSupregulated cells to SDF-1 or S1P gradients compared with the migration of control parental cells. Results are combined from three independent experiments. $* p \leq 0.05$

in these cells correlates with lower expression of HO-1 at the protein (Fig. 8C) and mRNA levels (Fig. 8D).

Finally, to address whether, vice versa, HO-1 overexpression affects iNOS expression, we employed the RAJI cell line, in which we overexpressed or downregulated HO-1 [5] and evaluated the iNOS mRNA level by real-time PCR (Supplementary Fig. 3A, C) and, in parallel, the NO levels in these cells (Supplementary Fig. 3B, D). We observed a positive correlation between HO-1 and iNOS expression.

\section{Discussion}

The most important observation of this report is that iNOS is a novel negative regulator of the trafficking of HSPCs, and this negative effect on cell migration is related to its effect on HO1 activity. Moreover, our results suggest that expression of iNOS and HO-1 is regulated in hematopoietic cells in a similar way. The inhibition of iNOS, as we reported for HO-1 [5, 6], 

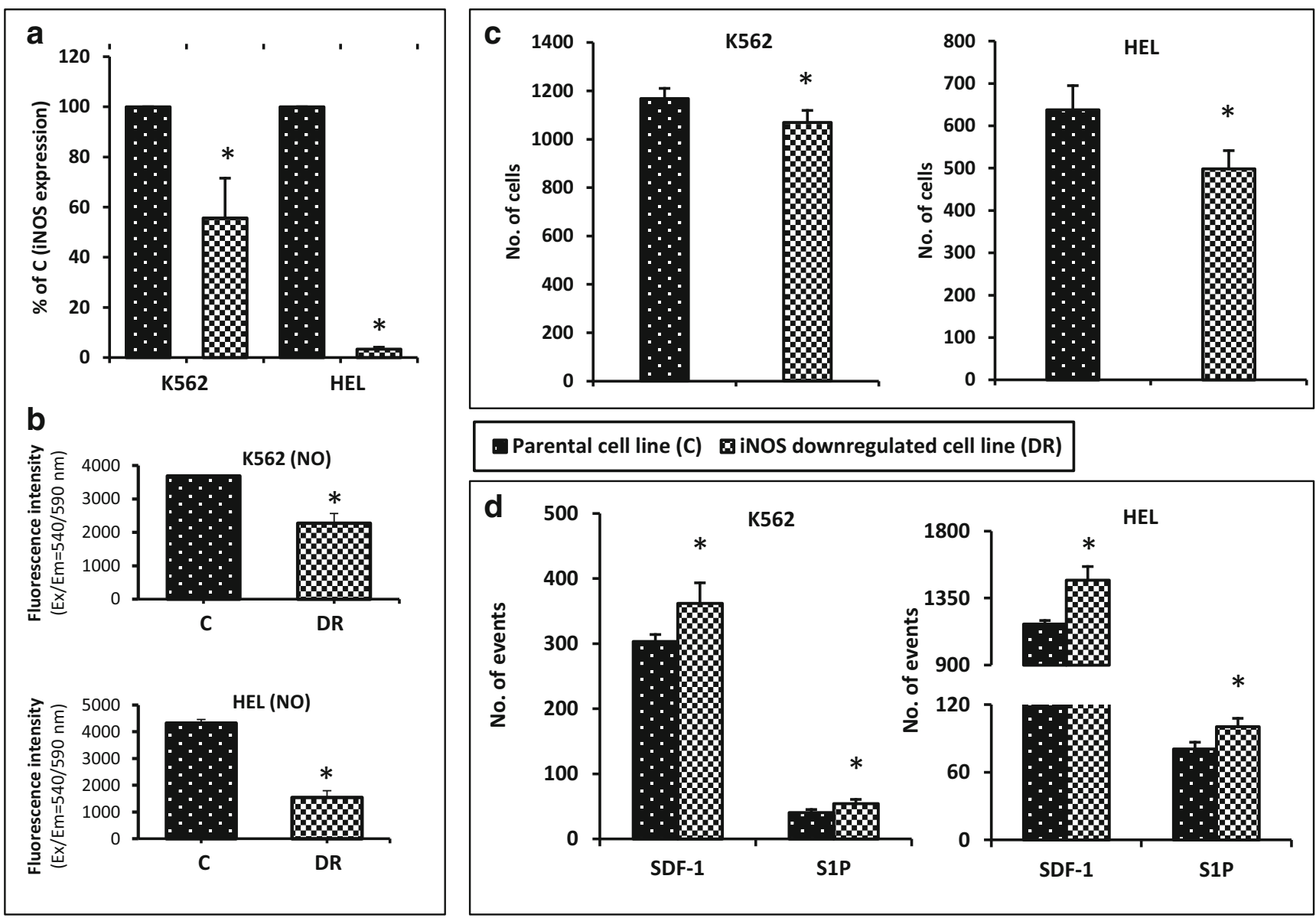

Fig. 2 Influence of iNOS downregulation on chemotaxis and adhesion of human hematopoietic cell lines (K562 and HEL). Panel A. iNOS expression was evaluated at the mRNA level by real-time PCR. Results from three independent experiments are pooled together. Panel B. Measurement of NO levels in the tested cell lines. $* p \leq 0.005$. Panel C. Fibronectin adhesion assay. The number of adherent cells is indicated,

may have practical applications in enhancing the homing of HSPCs to BM after transplantation as well as enhancing the mobilization of HSPCs from BM into PB in poor mobilizers.

In addition to hematopoietic cells, $\mathrm{NO}$ is also synthesized by many other cell types in the body in response to cytokines or stress situations, and its role is still not well understood. Initially, NO was considered to be mainly an antimicrobial, tumoricidal, and tissue-damaging effector molecule operating as part of the innate immune system [34-37]. However, today it is accepted that, in addition to innate immune responses, $\mathrm{NO}$ also strongly affects adaptive immune responses and exerts certain cytoprotective effects. It has been postulated that, in addition to pro-inflammatory effects, iNOS, and to some extent also other NOS isoforms (nNOS and eNOS), limits immune responses and has anti-inflammatory functions [11]. These include, for example, the eNOS-, iNOS-, or eNOSdependent inhibition of leukocyte adhesion and transendothelial migration [38, 39]. NO may also exert antiinflammatory effects by affecting polarization of macrophages and results from three separate experiments are pooled together. $* p \leq 0.01$. Panel D. The chemotactic responsiveness of iNOSdownregulated cells to SDF-1 or S1P gradients compared with migration of control parental cells. Results are combined from three independent experiments. $* \mathrm{p} \leq 0.05$

due to reduced proinflammatory M1 and increased antiinflammatory M2 phenotypic properties [15].

It is known that iNOS and HO- 1 are upregulated in parallel in response to infection and tissue or organ damage [36, 40, 41]. However, the mutual relationship between these stressinduced enzymes is still not very well understood. While overexpression of HO-1 or exposure of mouse or human cells to HO-1 hemin metabolism products $\left(\mathrm{CO}\right.$ or $\left.\mathrm{Fe}^{2+}\right)$ may suppress cytokine- or LPS-induced iNOS expression [42], on the other hand, depending on the cell system studied, NO may upregulate expression of HO-1 and its product $\mathrm{CO}$ [43].

We observed that in hematopoietic cells changes in expression of iNOS parallel changes in expression of HO-1. Thus, at the molecular level, one of the most plausible explanations for enhanced migration of HSPCs with downregulated iNOS could be because of the decrease of a negative regulator of cell migration, HO-1 [5, 6].

Our results also indicate that different isoforms of NOS may have different effects on cell trafficking. While 

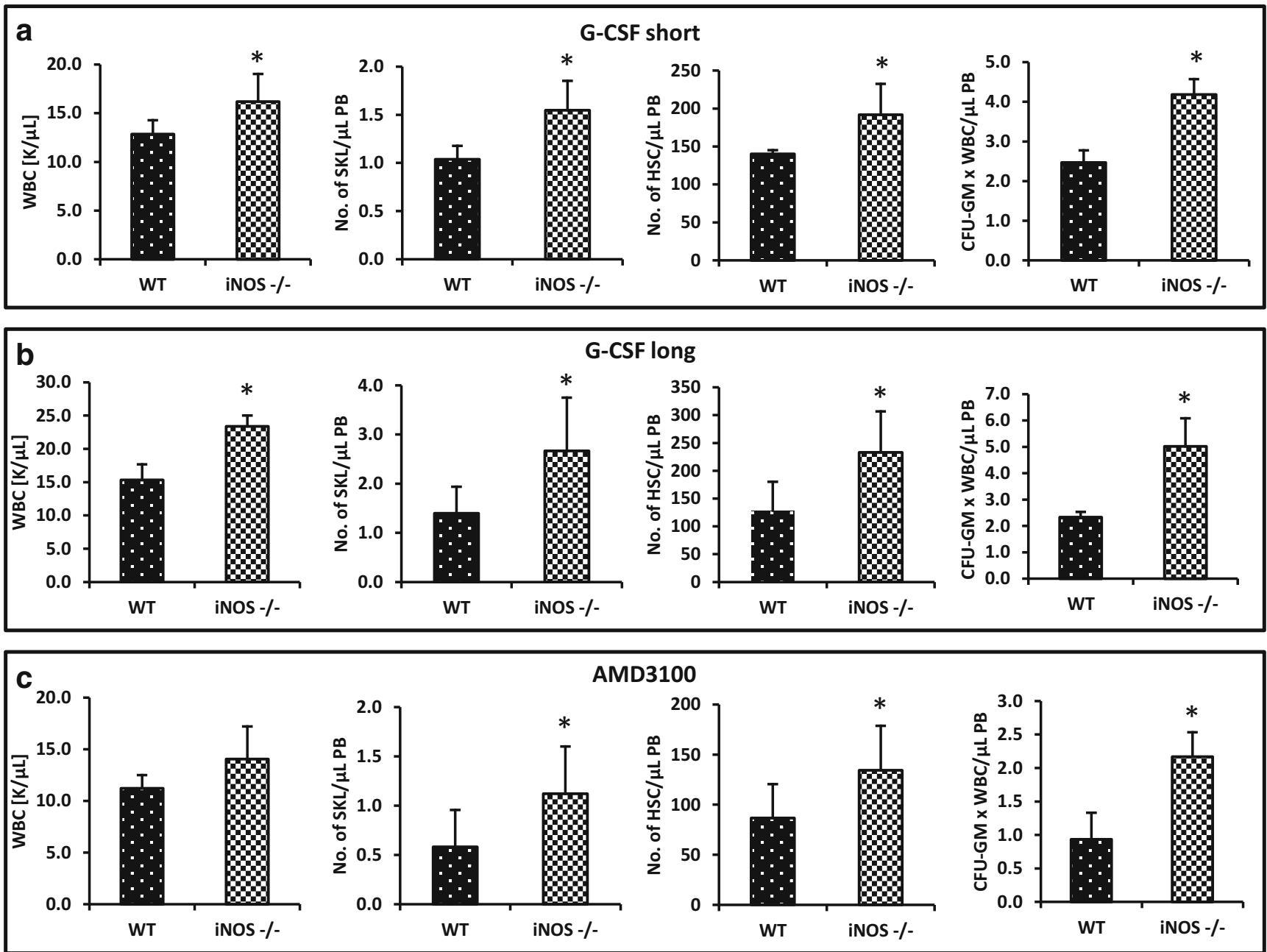

Fig. $3 \mathrm{iNOS}^{-/-}$mice are easily mobilized with G-CSF and AMD3100. MNCs were isolated from WT and $\mathrm{iNOS}^{-/-}$mice after 3-day (panel A) and 6-day (panel B) injections of G-CSF and a single dose of AMD3100 (panel C). Animals were killed $6 \mathrm{~h}$ after the last G-CSF injection and $1 \mathrm{~h}$

after AMD3100 mobilization, and the numbers of WBCs, SKL (Sca- $1^{+} \mathrm{c}-$ $\mathrm{kit}^{+} \mathrm{Lin}^{-}$) cells, HSCs (Sca- $\left.1^{+} \mathrm{CD} 45^{+} \mathrm{Lin}^{-}\right)$, and CFU-GM clonogenic progenitors from PB were evaluated. Results from two separate experiments are pooled together. $* \mathrm{p} \leq 0.05$

mobilization studies in eNOS-deficient mice revealed that constitutive expression of eNOS in endothelium is required

for mobilization of endothelial progenitor cells in response to VEGF stimulation [30], our results with hematopoietic cell-

Fig. 4 Impact of iNOS deficiency on the chemotactic activity of BMMNCs. The chemotactic responsiveness of $\mathrm{WT}$ and $\mathrm{iNOS}^{-/-}$-derived BMMNCs to SDF-1, S1P, C1P, and ATP gradients evaluated by FACS (panel A) and clonogenic CFU-GM progenitors (panel $B$ ). Results are combined from three independent

experiments. ${ }^{*} \mathrm{p} \leq 0.05$

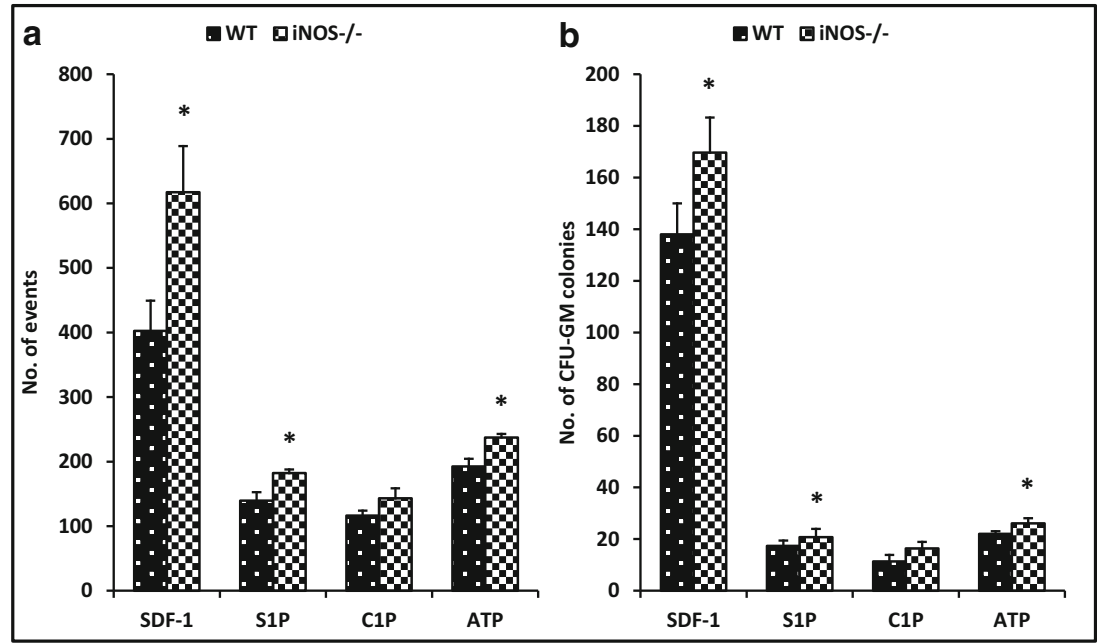




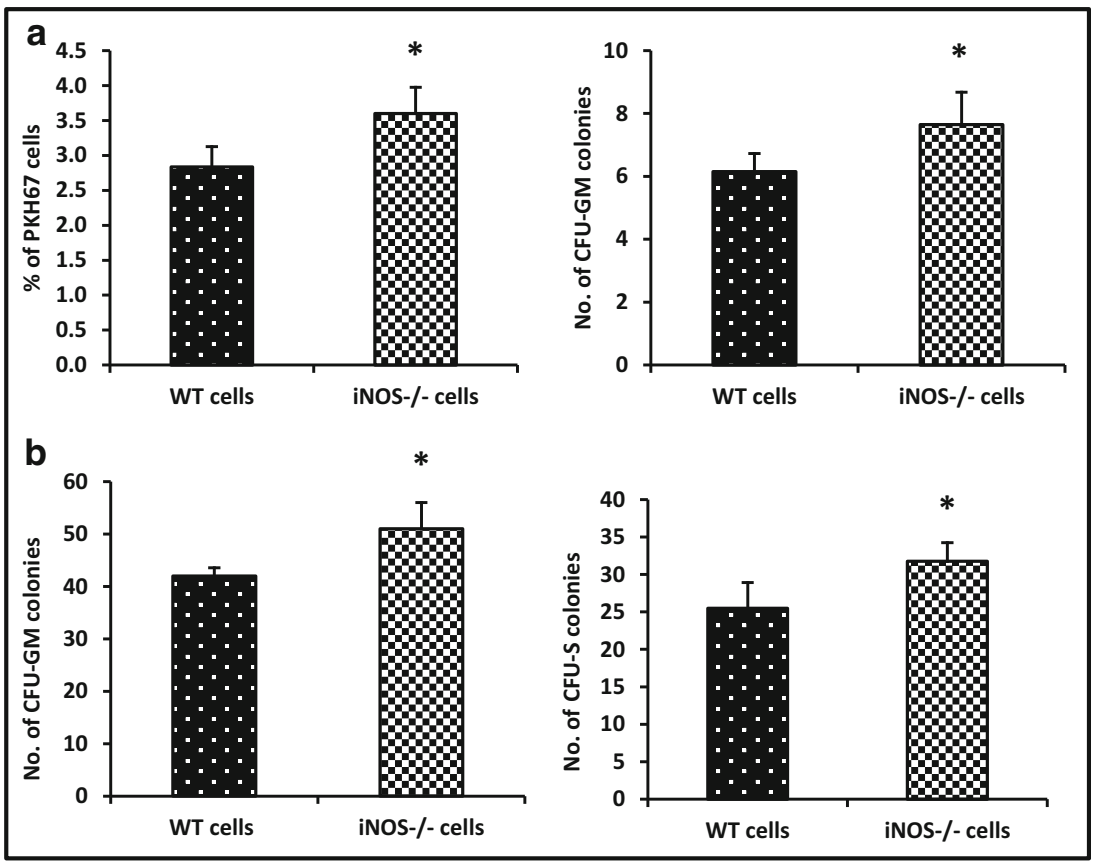

Fig. 5 Increase in homing and short-term engraftment of HSPCs from $\mathrm{iNOS}^{-/-}$mouse BM. Panel A. Lethally irradiated WT mice (six mice per group) were transplanted with $5 \times 10^{6} \mathrm{WT}_{\text {or }} \mathrm{iNOS}^{-/}$bone marrow mononuclear cells (BMMNCs) labeled with PKH67; $24 \mathrm{~h}$ after transplantation femoral BMMNCs were harvested; the number of labeled cells in murine BM was evaluated by FACS (panel A, left); and the number of clonogenic CFU-GM progenitors was enumerated in an in vitro colony assay (panel A, right). Panel B. Lethally irradiated WT mice (six mice per

group) were transplanted with $1.5 \times 10^{5} \mathrm{BMMNCs}_{\text {from } \mathrm{WT} \text { or iNOS }}^{-/}$ mice, and 12 days after transplantation femoral BMMNCs were harvested and plated to count the number of CFU-GM colonies (panel B, left), and spleens were removed for counting the number of CFU-S colonies (panel $B$, right). No colonies were formed in lethally irradiated and untransplanted mice (irradiation control). The data in panels A and B represent the combined results from two independent experiments $(n=10) . * p<0.005$

expressed iNOS indicate that this isoform has the opposite, anti-mobilization, effect on HSPCs in response to G-CSF and AMD3100. Since iNOS is also expressed in addition to constitutively expressed eNOS in endothelial cells, further studies

are needed to determine whether these nitric oxide synthases affect mobilization of endothelial progenitor cells in opposite ways. Moreover, taking into consideration the broad tissue expression of nNOS, it would be interesting to perform similar

Fig. 6 Accelerated engraftment of $\mathrm{iNOS}^{-/}$BMMNCs. Lethally irradiated WT mice were transplanted with $1 \times 10^{6}$ BMMNCs from WT or iNOS ${ }^{-1}$ cells. White blood cells (panel A) and platelets (panel $B$ ) were counted at intervals $(0,5,7,11$, 16,21 , and 28 days after transplantation). Results are combined from two independent experiments (six mice per group, $n=12) . * p<0.05$

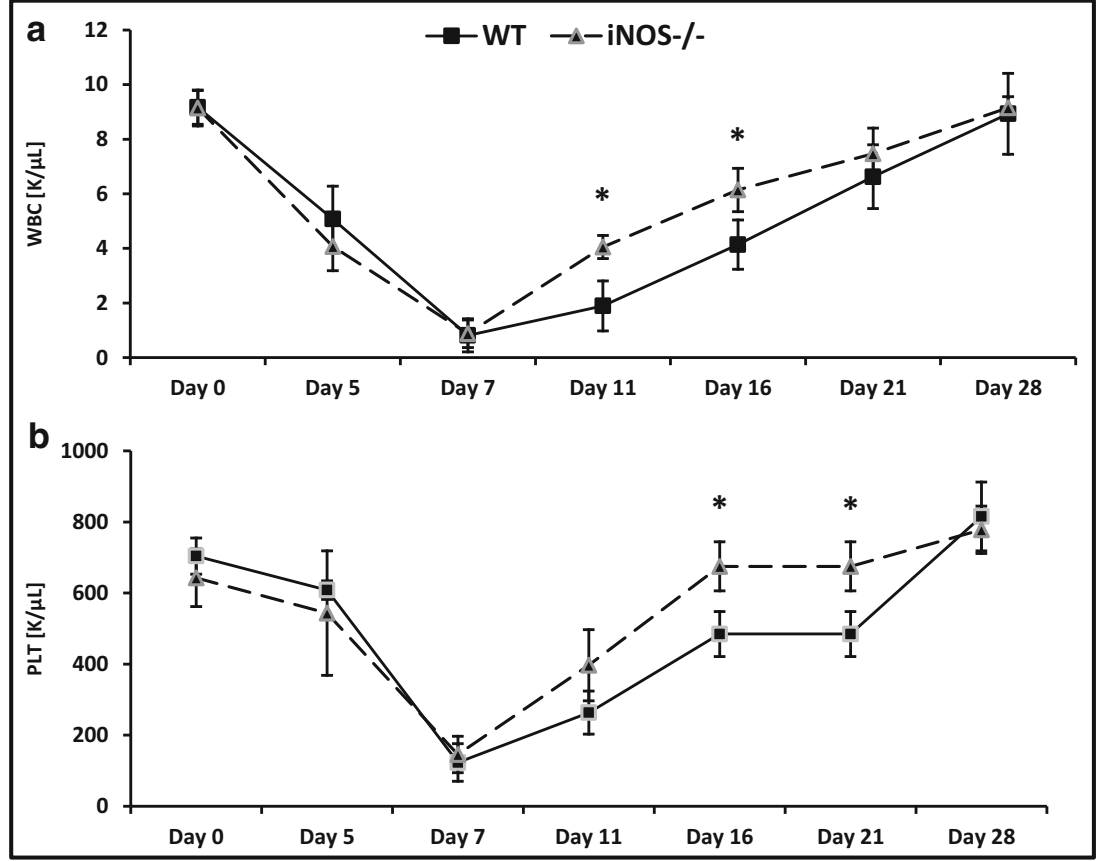




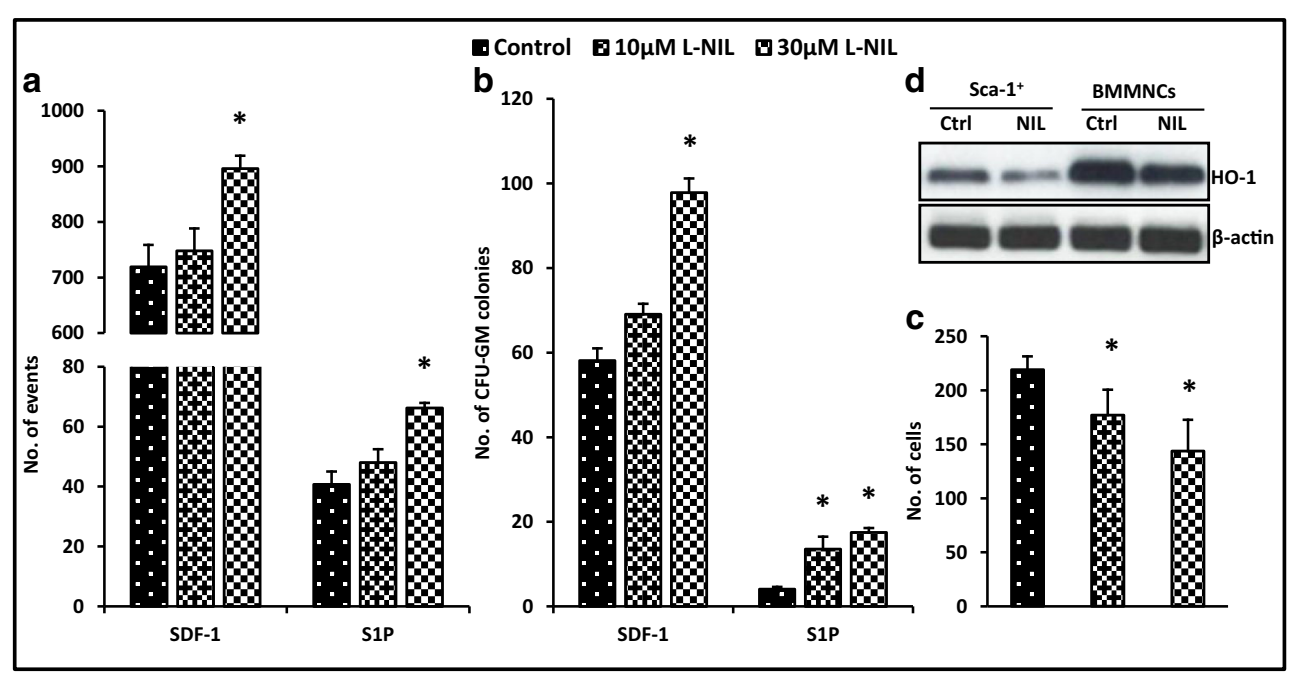

Fig. 7 The influence of an iNOS inhibitor (L-NIL) on chemotaxis and adhesion of murine BM-MNCs. The chemotactic responsiveness to SDF1 and S1P gradients of murine BMMNCs (evaluated by FACS) (Panel A) and clonogenic CFU-GM progenitors (Panel $B$ ) exposed to two different dosages of iNOS inhibitor. Results are combined from three independent experiments. ${ }^{*} p \leq 0.05$. Panel C. The effect of iNOS inhibition on

studies in $\mathrm{nNOS}^{-/}$animals [44]. In justification of such studies, nestin-positive cells that regulate stem cell trafficking have been described in BM [45, 46], and these cells could be potential effector cells for the biological effects of nNOS.

While several factors that enhance mobilization of HSPCs have been identified, very little is known about the physiological inhibitors of this process. In this context, our results with adhesion of murine BMMNCs to fibronectin. Data from four separate experiments are pooled together. $* p \leq 0.01$. Panel D. Detection of the HO-1 protein expression level by western blot in WT Sca- $1^{+}$cells and BMMNCs exposed to high doses of L-NIL. The same membranes were reprobed with $\beta$-actin to confirm equal loading of total protein

HO-1 $[5,6]$ and with iNOS that are reported here shed new light on regulation of this process. Since excessive inflammation mediated by ComC activation contributes to various complications (e,g., sepsis), it is important to identify molecules that attenuate complement-mediated inflammation. Thus, further studies are needed to better understand the reciprocal relationship between activation of the $\mathrm{ComC}$, which may
Fig. 8 Correlation between iNOS up- and downregulation and $\mathrm{HO}-1$ expression in experimental hematopoietic cell lines. Panels A and C. Expression of HO-1 following iNOS upregulation (Panel $A)$ or downregulation (Panel $C$ ) was evaluated at the protein level by western blotting, and representative blots and their densitometry analysis are shown (upper and lower panels, respectively). The same membranes were reprobed with $\beta$-actin to confirm equal loading of total protein. Panel B and D. In parallel, HO-1 expression in the cells employed was assessed at the mRNA level by real-time PCR. Results from three independent experiments are pooled together. $* p \leq 0.005$

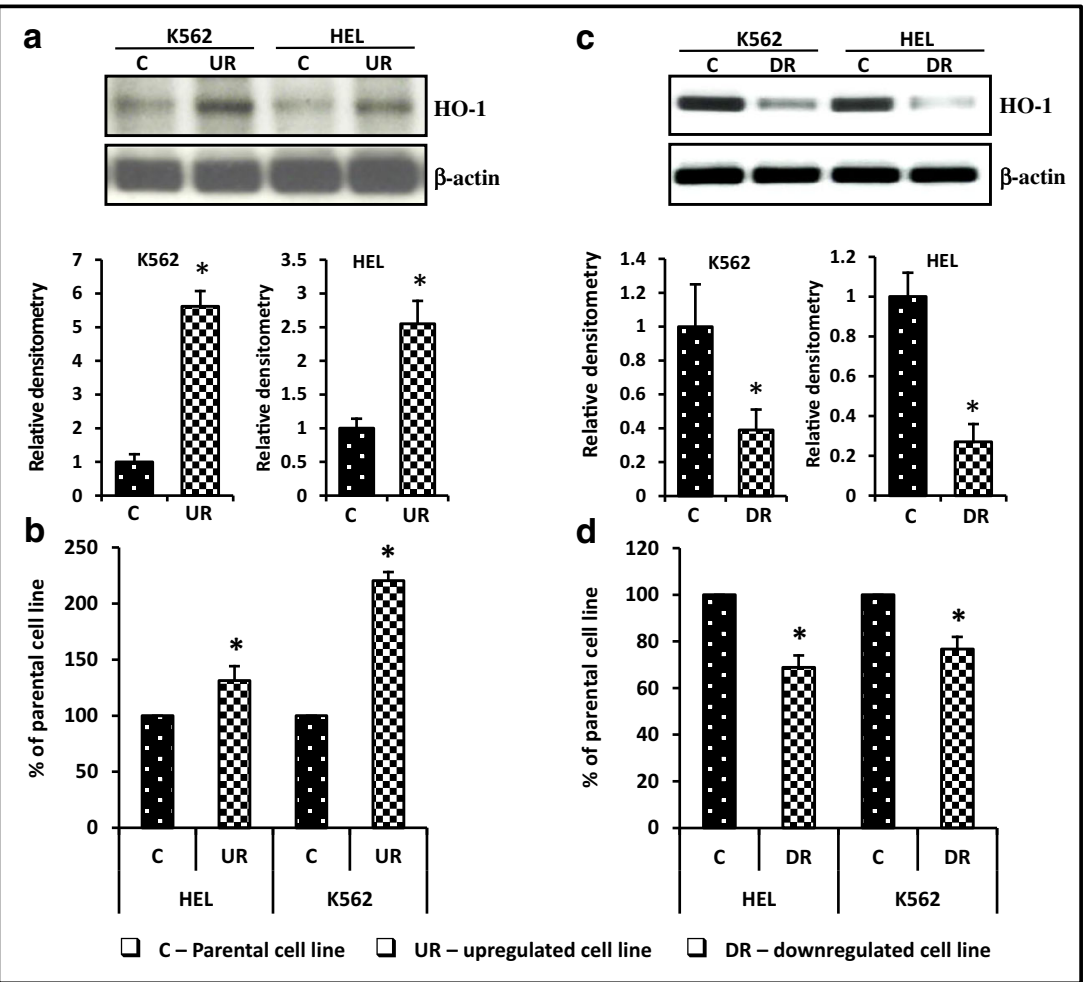


initially promote expression of both of these stress-induced enzymes, and the subsequent negative feedback that limits activation of the ComC. In support of such a relationship, it is know that biliverdin and bilirubin are potent inhibitors of activation of the ComC by inhibiting its activation directly in the classical pathway of ComC activation at the $\mathrm{C} 1$ level by physically interacting with complement proteins $[8,47]$ and by modulating expression of C5aR [7]. This modulation has important implications for the mobilization process, as the $\mathrm{C} 5 \mathrm{a}-\mathrm{C} 5 \mathrm{aR}$ interaction is crucial for promoting egress of HSPCs from BM into PB, and mice deficient in C5a or C5aR are poor mobilizers [2].

In conclusion, we have demonstrated for the first time that iNOS plays an important role in mobilization as well as engraftment of HSPCs. Further studies are needed to confirm whether modulation of iNOS in human HSPCs, as in their murine counterparts, could be employed as a novel strategy to enhance homing and accelerate engraftment of HSPCs after transplantation. This would be important, particularly in clinical situations in which the number of HSPCs to be transplanted is low (e.g., from poor-mobilizing donors or UCB transplantations) or, on the other hand, in patients that are poor mobilizers in response to classical pro-mobilizing agents.

Acknowledgments This work was supported by NIH grants 2R01 DK074720 and R01HL112788, the Stella and Henry Endowment, and the Harmonia NCN grant UMO-2014/14/M/NZ3/00475 to MZR. AAI was on leave of absence from the Faculty of Veterinary Medicine, Zagazig University, Egypt.

\section{Compliance with Ethical Standards}

Conflict of Interest Statement The authors declare that they have no competing financial interests.

Open Access This article is distributed under the terms of the Creative Commons Attribution 4.0 International License (http:// creativecommons.org/licenses/by/4.0/), which permits unrestricted use, distribution, and reproduction in any medium, provided you give appropriate credit to the original author(s) and the source, provide a link to the Creative Commons license, and indicate if changes were made.

\section{References}

1. Borkowska, S., Suszynska, M., Ratajczak, J., et al. (2016). Evidence of a pivotal role for the distal part of the complement cascade in the diurnal release of hematopoietic stem cells into peripheral blood. Cell Transplantation, 25, 275-282.

2. Lee, H., Wu, W., Wysoczynski, M., et al. (2009). Impaired mobilization of hematopoietic stem/progenitor cells in C5-deficient mice supports the pivotal involvement of innate immunity in this process and reveals novel promobilization effects of granulocytes. Leukemia, 23, 2052-2062.

3. Lee, H., Wysoczynski, M., Liu, R., et al. (2010). Mobilization studies in complement-deficient mice reveal that optimal AMD3100 mobilization of hematopoietic stem cells depends on complement cascade activation by AMD3100-stimulated granulocytes. Leukemia, 24, 573-582.

4. Wysoczynski, M., Reca, R., Lee, H., et al. (2009). Defective engraftment of $\mathrm{C} 3 \mathrm{aR}-/-$ hematopoietic stem progenitor cells shows a novel role of the $\mathrm{C} 3 \mathrm{a}-\mathrm{C} 3 \mathrm{aR}$ axis in bone marrow homing. Leukemia, 23, 1455-1461.

5. Adamiak, M., Moore, J., Zhao, J., et al. (2016). Downregulation of heme oxygenase 1 (HO-1) activity in hematopoietic cells enhances their engraftment after transplantation. Cell Transplantation, 25, $1265-1276$.

6. Wysoczynski, M., Ratajczak, J., Pedziwiatr, D., et al. (2015). Identification of heme oxygenase 1 (HO-1) as a novel negative regulator of mobilization of hematopoietic stem/progenitor cells. Stem Cell Reviews, 11, 110-118.

7. Bisht, K., Wegiel, B., Tampe, J., et al. (2014). Biliverdin modulates the expression of $\mathrm{C} 5 \mathrm{aR}$ in response to endotoxin in part via mTOR signaling. Biochemical and Biophysical Research Communications, 449, 94-99.

8. Kinderlerer, A., Pombo Gregoire, I., Hamdulay, S., et al. (2009). Heme oxygenase-1 expression enhances vascular endothelial resistance to complement-mediated injury through induction of decayaccelerating factor: a role for increased bilirubin and ferritin. Blood, 113, 1598-1607.

9. Tenhunen, R., Marver, H., \& Schmid, R. (1968). The enzymatic conversion of heme to bilirubin by microsomal heme oxygenase. Proceedings of the National Academy of Sciences of the United States of America, 61, 748-755.

10. Bogdan, C. (2001). Nitric oxide and the immune response. Nature Immunology, 2, 907-916.

11. Bogdan, C. (2015). Nitric oxide synthase in innate and adaptive immunity: an update. Trends in Immunology, 36, 161-178.

12. Huang, Z., Hoffmann, F., Fay, J., et al. (2012). Stimulation of unprimed macrophages with immune complexes triggers a low output of nitric oxide by calcium-dependent neuronal nitric-oxide synthase. The Journal of Biological Chemistry, 287, 4492-4502.

13. Martinelli, R., Gegg, M., Longbottom, R., et al. (2009). ICAM-1-mediated endothelial nitric oxide synthase activation via calcium and AMP-activated protein kinase is required for transendothelial lymphocyte migration. Molecular Biology of the Cell, 20, 995-1005.

14. Nathan, C. (1992). Nitric oxide as a secretory product of mammalian cells. The Federation of American Societies for Experimental Biology, 6, 3051-3064.

15. Lee, W., Tateya, S., Cheng, A., et al. (2015). M2 macrophage polarization mediates anti-inflammatory effects of endothelial nitric oxide signaling. Diabetes, 64, 2836-2846.

16. Montalto, M., Hart, M., Jordan, J., et al. (2003). Role for complement in mediating intestinal nitric oxide synthase-2 and superoxide dismutase expression. American Journal of Physiology Gastrointestinal and Liver Physiology, 285, 197-206.

17. Tziros, C., \& Freedman, J. (2006). The many antithrombotic actions of nitric oxide. Current Drug Targets, 7, 1243-1251.

18. Vincent, S. (2010). Nitric oxide neurons and neurotransmission. Progress in Neurobiology, 90, 246-255.

19. Jalili, A., Shirvaikar, N., Marquez-Curtism, L., et al. (2010). Fifth complement cascade protein (C5) cleavage fragments disrupt the SDF-1/CXCR4 axis: further evidence that innate immunity orchestrates the mobilization of hematopoietic stem/progenitor cells. Experimental Hematology, 38, 321-332.

20. Adamiak, M., Borkowska, S., Wysoczynski, M., et al. (2015). Evidence for the involvement of sphingosine-1-phosphate in the homing and engraftment of hematopoietic stem cells to bone marrow. Oncotarget, 6, 18819-18828.

21. Adamiak, M., Poniewierska-Baran, A., Borkowska, S., et al. (2015). Evidence that a lipolytic enzyme-hematopoietic-specific 
phospholipase C-beta2-promotes mobilization of hematopoietic stem cells by decreasing their lipid raft-mediated bone marrow retention and increasing the promobilizing effects of granulocytes. Leukemia, 30, 919-928.

22. Christopher, M., Rao, M., Liu, F., et al. (2011). Expression of the GCSF receptor in monocytic cells is sufficient to mediate hematopoietic progenitor mobilization by G-CSF in mice. The Journal of Experimental Medicine, 208, 251-260.

23. Kim, C., Wu, W., Wysoczynski, M., et al. (2012). Conditioning for hematopoietic transplantation activates the complement cascade and induces a proteolytic environment in bone marrow: a novel role for bioactive lipids and soluble $\mathrm{C} 5 \mathrm{~b}-\mathrm{C} 9$ as homing factors. Leukemia, 26, 106-116.

24. Levesque, J., Takamatsu, Y., Nilsson, S., et al. (2001). Vascular cell adhesion molecule-1 (CD106) is cleaved by neutrophil proteases in the bone marrow following hematopoietic progenitor cell mobilization by granulocyte colonystimulating factor. Blood, 98, 1289-1297.

25. Pruijt, J., Verzaal, P., van Os, R., et al. (2002). Neutrophils are indispensable for hematopoietic stem cell mobilization induced by interleukin-8 in mice. Proceedings of the National Academy of Sciences of the United States of America, 99, 6228-6233.

26. Ratajczak, M. Z., Kim, C., Wu, W., et al. (2012). The role of innate immunity in trafficking of hematopoietic stem cells-an emerging link between activation of complement cascade and chemotactic gradients of bioactive sphingolipids. Advances in Experimental Medicine and Biology, 946, 37-54.

27. Ratajczak, M. Z., \& Suszynska, M. (2016). Emerging strategies to enhance homing and engraftment of hematopoietic stem cells. Stem Cell Reviews, 12, 121-128.

28. Singh, P., Hu, P., Hoggatt, J., Moh, A., et al. (2012). Expansion of bone marrow neutrophils following G-CSF administration in mice results in osteolineage cell apoptosis and mobilization of hematopoietic stem and progenitor cells. Leukemia, 26, 2375-2383.

29. Jiang, Z., Fletcher, N., Diamond, M., et al. (2009). Hypoxia regulates iNOS expression in human normal peritoneal and adhesion fibroblasts through nuclear factor kappa B activation mechanism. Fertility and Sterility, 91, 616-621.

30. Aicher, A., Heeschen, C., Mildner-Rihm, C., et al. (2003). Essential role of endothelial nitric oxide synthase for mobilization of stem and progenitor cells. Nature Medicine, 9, 1370-1376.

31. Nolan, S., Dixon, R., Norman, K., et al. (2008). Nitric oxide regulates neutrophil migration through microparticle formation. The American Journal of Pathology, 172, 265-273.

32. Wanikiat, P., Woodward, D., \& Armstrong, R. (1997). Investigation of the role of nitric oxide and cyclic GMP in both the activation and inhibition of human neutrophils. British Journal of Pharmacology, $122,1135-1145$

33. Abdelbaset-Ismail, A., Borkowska-Rzeszotek, S., Kubis, E., et al. (2016). Activation of the complement cascade enhances motility of leukemic cells by downregulating expression of HO-1. Leukemia. doi:10.1038/leu.2016.198 [Epub ahead of print].

34. Laroux, F., Lefer, D., Kawachi, S., et al. (2000). Role of nitric oxide in the regulation of acute and chronic inflammation. Antioxidants \& Redox Signaling, 2, 391-396.

35. Munoz-Fernandez, M., Fernandez, M., \& Fresno, M. (1992). Activation of human macrophages for the killing of intracellular Trypanosoma cruzi by TNF-alpha and IFN-gamma through a nitric oxide-dependent mechanism. Immunology Letters, 33, 35-40.

36. Pindado, J., Balsinde, J., \& Balboa, M. (2007). TLR3-dependent induction of nitric oxide synthase in RAW 264.7 macrophage-like cells via a cytosolic phospholipase A2/cyclooxygenase-2 pathway. The Journal of Immunology, 179, 4821-4828.

37. Vannini, F., Kashfi, K., \& Nath, N. (2015). The dual role of iNOS in cancer. Redox Biology, 6, 334-343.

38. Dal, S. D., Paron, J. A., de Oliveira, S. H., et al. (2003). Neutrophil migration in inflammation: nitric oxide inhibits rolling, adhesion and induces apoptosis. Nitric Oxide, 9, 153-164.

39. Alves-Filho, J. C., de Freitas, A., Spiller, F., et al. (2008). The role of neutrophils in severe sepsis. Shock, 30(Suppl 1), 3-9.

40. Hierholzer, C., Harbrecht, B., Menezes, J., et al. (1998). Essential role of induced nitric oxide in the initiation of the inflammatory response after hemorrhagic shock. The Journal of Experimental Medicine, 187, 917-928.

41. Sumi, D., \& Ignarro, L. (2004). Regulation of inducible nitric oxide synthase expression in advanced glycation end product-stimulated raw 264.7 cells: the role of heme oxygenase- 1 and endogenous nitric oxide. Diabetes, 53, 1841-1850.

42. Datta, P., Koukouritaki, S., Hopp, K., et al. (1999). Heme oxygenase-1 induction attenuates inducible nitric oxide synthase expression and proteinuria in glomerulonephritis. Journal of the American Society of Nephrology, 10, 2540-2550.

43. Durante, W., Kroll, M., Christodoulides, N., et al. (1997). Nitric oxide induces heme oxygenase-1 gene expression and carbon monoxide production in vascular smooth muscle cells. Circulation Research, 80, 557-564.

44. Zhou, L., Bai, R., Tian, J., et al. (2009). Bioinformatic comparisons and tissue expression of the neuronal nitric oxide synthase (nNOS) gene from the red drum (Sciaenops ocellatus). Fish \& Shellfish Immunology, 27, 577-584.

45. Mendelson, A., \& Frenette, P. (2014). Hematopoietic stem cell niche maintenance during homeostasis and regeneration. Nature Medicine, 20, 833-846.

46. Morrison, S., \& Scadden, D. (2014). The bone marrow niche for haematopoietic stem cells. Nature, 505, 327-334.

47. Basiglio, C., Arriaga, S., Pelusa, F., et al. (2010). Complement activation and disease: protective effects of hyperbilirubinaemia. Clinical Science (London), 118, 99-113. 